\title{
HLA DQ Beta1 Histocompatibility Antigen Measurement
}

National Cancer Institute

\section{Source}

National Cancer Institute. HLA DQ Beta1 Histocompatibility Antigen Measurement. NCI Thesaurus. Code C154750.

The determination of the amount of HLA DQ beta1 histocompatibility antigen present in a sample. 